suas propriedades óticas. O objetivo deste estudo consistiu em comparar a translucidez de diferentes espessuras de zircónia.

Materiais e métodos: Foram fresados 20 espécimes de zircónia monolítica ultra-translúcida (Bloomden W00098014UT), pré-sinterizada, através de um sistema computer-aided design / computer-aided manufacturing (Wieland Dental). Definiram-se 4 grupos $(n=5)$ de acordo com a espessura da zircónia: 0,5, 1,0, 1,5 e 2,0 mm. Todos os espécimes foram corados de A2 (BloomZir ${ }^{\circledR}$ UT Coping Crown A2), durante 2 minutos e sinterizados no forno (IMES-Wieland Zeno ${ }^{\circledR}$ Fire) a temperaturas entre os $1500 .^{\circ} \mathrm{C}$ e $1550 .{ }^{\circ} \mathrm{C}$, segundo as indicações do fabricante. Por fim, todos os espécimes foram submetidos a um banho de ultrassons (VGT-2120QTD 20L). Os valores de L*, $a^{*}$ e b* foram medidos, sob luz natural (D65), através do espectrofotómetro SpectroShade Micro em 6 localizações distintas sobre um fundo branco (Comission Internationale de l' Éclairage (CIE) $\mathrm{L}^{*}=$ $\left.95,6 a^{*}=0,8 b^{*}=0,1\right)$ e sobre um fundo preto (Comission Internationale de l' Éclairage (CIE) $\left.L^{*}=13,2 a^{*}=0,8 b^{*}=-0,7\right)$. A translucidez dos espécimes foi calculada através de duas fórmulas distintas: a relação de contraste $\left(C R=\mathrm{L}_{\mathrm{b}} / \mathrm{L}_{\mathrm{w}}\right)$ e o parâmetro de translucidez $\left(\mathrm{TP}=\left[\left(\mathrm{L}_{\mathrm{b}}-\mathrm{L}_{\mathrm{w}}\right)^{2}+\left(\mathrm{a}_{\mathrm{b}}-\mathrm{a}_{\mathrm{w}}\right)^{2}+\left(\mathrm{b}_{\mathrm{b}}-\mathrm{b}_{\mathrm{w}}\right)^{2}\right]^{1 / 2}\right)$. A análise dos resultados foi efetuada com recurso a estatística descritiva.

Resultados: Os valores da relação de contraste obtidos variaram entre $0,7 \pm 0,0$ e $0,9 \pm 0,0$ e os valores do parâmetro de translucidez entre $14,1 \pm 0,3$ e $26,7 \pm 0,4$. Com o aumento da espessura verificou-se um decréscimo na translucidez.

Conclusões: A translucidez da zircónia monolítica ultra-translúcida apresentou uma relação inversamente proporcional à sua espessura.

http://doi.org/10.24873/j.rpemd.2018.11.360

\section{\#127 Desinfeção de impressões em Silicone de adição: Estabilidade Dimensional/Carga Microbiana}

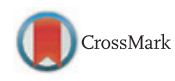

Maria João Azevedo*, Inês Correia, Benedita Sampaio-Maia, Ana Isabel Portela

Faculdade de Medicina Dentária da Universidade do Porto

Objetivos: Os materiais de impressão com maior definição, como os silicones de adição, são vastamente utilizados em Medicina Dentária. Pretende-se que a desinfeção das impressões seja eficaz e que não interfira com a estabilidade dimensional das mesmas. Idealmente, o maior poder antimicrobiano deve estar associado ao menor impacto na estabilidade dimensional. Para o efeito, foram avaliadas diferentes soluções desinfetantes, utilizadas na prática clínica diária, de forma a determinar qual a mais adequada.

Materiais e métodos: A cada participante foi realizada uma impressão parcial em silicone de adição (Hydrorise Putty, Zhermack $^{\mathrm{TM}}$ ). Foi avaliada a eficácia antimicrobiana e as alterações dimensionais (de acordo com a norma ISO 4823:2015) induzidas pela lavagem com água (30 segundos) e pelos seguintes desinfetantes, após lavagem com água corrente por 15 segundos: $\left.\mathrm{MD}^{2}{ }^{\circledR}{ }^{(D u r r}{ }^{\mathrm{TM}}\right)$, hipoclorito de sódio 1\%, hipoclorito de sódio 5,25\% e peróxido de hidrogénio 3\%. Para a análise estatística, foi utilizado o software IBM SPSS $24^{\circledR}$. Foi testada a normalidade das amostras (teste Shapiro-Wilk) e, dependendo dos resultados, foram aplicados testes ANOVA ou Kruskal-Wallis. O nível mínimo de significância foi de 5\%, com a correção de Bonferroni para múltiplas comparações.

Resultados: Na avaliação da eficácia antimicrobiana, a lavagem com água reduziu ineficazmente a carga microbiana $(11,72 \%, p>0,05)$. Houve diferenças estatisticamente significativas entre as taxas de redução observadas através da lavagem com água e a dos diferentes desinfetantes $(p<0,001)$. A taxa de redução da carga microbiana após desinfeção foi sempre superior a 99,9\%. Na avaliação da estabilidade dimensional, não houve diferenças significativas entre as alterações dimensionais observadas entre os diferentes protocolos de desinfeção, a lavagem com água 30 segundos e o controlo não lavado ( $>>0,05)$.

Conclusões: As alterações dimensionais observadas após a aplicação dos diferentes protocolos de desinfeção são clinicamente aceitáveis e estão dentro do intervalo protocolado pela norma ISO 4823:2015. A lavagem com água não é eficaz na redução da carga microbiana quando comparada com os diferentes desinfetantes. Neste sentido, qualquer um dos desinfetantes deverá ser sempre utilizado em suplemento à lavagem com água, para reduzir significativamente a carga microbiana.

http://doi.org/10.24873/j.rpemd.2018.11.361

\#128 Erros na preparação dentária no setor posterior em prótese fixa

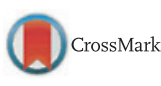

Margaux Sandy Silva*, Paulo Júlio Almeida, Paula Vaz, Francisco Góis, J.C Reis Campos, César Silva

Faculdade de Medicina Dentária da Universidade do Porto

Objetivos: Avaliar quais os principais erros efetuados pelo estudante de Prótese Fixa no ensino pré-clínico na Faculdade de Medicina Dentária da Universidade do Porto (FMDUP), através da análise de preparações dentárias efetuadas em dentes posteriores para coroa cerâmica. Almejou-se ainda estimar a existência de discrepância, na avaliação destes dentes, de acordo com o grau de experiência do avaliador.

Materiais e métodos: A amostra foi composta por 202 dentes pré-molares superiores, de modelo Frasaco ${ }^{\circledR}$, preparados para coroa cerâmica pura, por estudantes do $4 .^{\circ}$ ano da Unidade Curricular de Prótese Fixa II, da Faculdade de Medicina Dentária da Universidade do Porto. Esta amostra foi dividida equitativamente em dois grupos: A - preparados em mão e B - preparados no Fantoma ${ }^{\circledR}$. Os dois grupos foram avaliados por dois avaliadores, um sénior (Professor Sénior de Prótese Fixa) e um Júnior (estudante finalista do Mestrado Integrado) da FMDUP, atribuindo classificação de 1 a 5, para 3 critérios (desgaste axial, posição da linha de acabamento e desgaste oclusal). Foi efetuada uma análise comparativa entre as avaliações de cada avaliador e quantificada a discrepância inter-avaliador, recorrendo ao software SPSS $^{\circledR}$ statistics (USA) e ao coeficiente Kappa de Fleiss (k).

Resultados: Os erros mais frequentemente encontrados, surgiram no grupo A. O erro principalmente encontrado, nos dois grupos (A e B), ocorreu no desgaste oclusal. Os erros menos comuns nas preparações dentárias nos dois grupos (A e B) foram na redução axial e na posição cervical da linha de aca- 